\section{Identification of Retinoic Acid Receptor Agonists in Sewage Treatment Plants}

\author{
HUAJUN ZHEN, ${ }^{\dagger}$ XIAOQIN WU, ${ }^{\dagger}$ \\ JIANYING HU, ${ }^{*},{ }^{\dagger}$ YANG XIAO,${ }^{\dagger}$ \\ MIN YANG, ${ }^{\ddagger}$ JUNJI HIROTSUJI, ${ }^{\S}$ \\ JUN-ICHI NISHIKAWA," \\ TSUYOSHI NAKANISHI, ${ }^{\perp}$ AND \\ M I C H I H I K O I KE ${ }^{\#}$
}

Laboratory for Earth Surface Processes, College of Urban and Environmental Sciences, Peking University, Beijing 100871, China, State Key Lab of Environmental Aquatic Chemistry, Research Center for Eco-Environmental Sciences, Chinese Academy of Sciences, Beijing 100085, China, Advanced Technology R\&D Center, Mitsubishi Electric Co., 8-1-1 Tsukaguchi-Honmachi, Amagasaki, Hyogo 661-8661, Japan, Department of Pharmacology, Faculty of Pharmaceutical Sciences, Mukogawa Women's University, 11-68 Koshien Kyubancho, Nishinomiya City, Japan, Laboratory of Hygienics, Gifu Pharmaceutical University, 5-6-1 Mitahora-higashi, Gifu 502-8585, Japan, and Division of Sustainable Energy and Environmental Engineering, Graduate School of Engineering, Osaka University, 2-1 Yamadaoka, Suita, Osaka 565-0871, Japan

Received July 12, 2008. Revised manuscript received July 13, 2009. Accepted July 19, 2009.

Retinoic acid receptor (RAR) agonists are speculated to be one possible cause for the widely observed frog deformities in North America, although little is known about the specific RAR agonists in aquatic environments. We identified the specific RAR agonists in sewage treatment plants (STPs) and receiving rivers using an RAR yeast two-hybrid bioassay. Water samples were extracted by solid-phase extract cartridges, which were successively eluted by hexane, ethyl acetate, and methanol for bioassay. Among the three fractions, the ethyl acetate fraction showed the highest RAR agonistic activities. The bioassay-derived activity, expressed as all-trans-retinoic acid (all-trans-RA) equivalents (ATRA-EO) were $10.9 \pm 2.2$ and 1.7 $\pm 1.0 \mathrm{ng} / \mathrm{L}$ in the STP influents and effluents, respectively, while the ATRA-EOs were as high as 7.1 and $8.3 \mathrm{ng} / \mathrm{L}$ in the two rivers receiving STP effluents. Following a two-step fractionation using high-performance liquid chromatography and ultraperformance liquid chromatography (UPLC) directed by the bioassay, two bioactive fractions were obtained from Gaobeidian STP influent and all-trans-4-0xo-RA (4.7-10.4 ng/L in influents, $<0.2-0.9 \mathrm{ng} / \mathrm{L}$ in effluents) and 13-cis-4-oxo-RA (2.3-7.1 $\mathrm{ng} / \mathrm{L}$ in influents, $<0.4-1.1 \mathrm{ng} / \mathrm{L}$ in effluents) were identified in these fractions with UPLC-MS/MS. The $\mathrm{EC}_{50}$ for all-trans-4-

* Corresponding author phone and fax: 86-10-62765520; e-mail: hujy@urban.pku.edu.cn.

${ }^{\dagger}$ Peking University.

₹ Chinese Academy of Sciences.

${ }^{\S}$ Mitsubishi Electric Co.

"Mukogawa Women's University.

${ }^{\perp}$ Gifu Pharmaceutical University.

" Osaka University.
oxo-RA or 13-cis-4-oxo-RA relative to that of all-trans-RA in exhibiting RAR $\alpha$ agonistic activity was calculated to be 3.87 and 0.46 , respectively.

\section{Introduction}

A number of papers have highlighted the potentially detrimental effects of naturally occurring and man-made chemicals on reproductive and developmental processes in wildlife and humans $(1-4)$. Previous studies have paid special attention to some endocrine-disrupting chemicals which exert estrogenic activity via binding to the estrogen receptor (ER), through which the ligand-receptor complex subsequently activates transcription of target genes (5-7). There exist a number of nuclear hormone receptors such as the ER, androgen receptor (AR), thyroid receptor (TR), retinoic acid receptor (RAR), and vitamin D receptor (VDR), which mediate the actions of hormones and vitamins to affect processes from reproduction to development and even general metabolism (8). Thus, environmental pollutants binding to a wide variety of nuclear hormone receptors could induce adverse effects in wildlife (9), as exemplified by a recent study that organotins caused imposex in gastropods through the involvement of retinoid X receptors (RXRs) (10).

As one of these nuclear hormone receptors, RARs, which include three subtypes $\alpha, \beta$, and $\gamma$, are raising the concern of environmental scientists. RARs control aspects of vision, cell differentiation, immune response, and also embryonic development in vertebrates (11). Ligands of RARs have been reported to be potential teratogens in developing embryos, and an agonist specific for each subtype exhibits different teratogenic patterns. RAR $\alpha$ ligand causes deformity in the ear and mandible, and causes limb malformations, while $\operatorname{RAR} \beta$ agonist induces malformations in the liver and urinary system, and the ligand for RAR $\gamma$ causes ossification deficiencies and defects of the sternabrae and vertebral bodies (12). The natural ligands for RARs are endogenous retinoic acids (RAs) derived from retinoid (vitamin A) precursors (13). An excess or a deficiency of RA and related retinoids can cause abnormal morphological development, which was proven to be an RAR-mediated process (12). It was found that treating the larvae of Japanese flounder (Paralichthys olivaceus) with RA would cause deformities in the lower jaw, caudal fin, and vertebrae (14). Previous studies with Xenopus laevis have shown that exposure to RA or the RA precursor, retinyl palmitate, would induce malformations in eyes and hindlimbs (15-18), and similar phenomena including eye abnormalities, extra/missing limbs and/or digits have also been observed in wild frogs (19-22). Accordingly, the presence of RAR agonists was suggested to be one possible cause for the increasing trend of wildlife malformation $(18,23)$.

The natural RAs, which are derived from retinoid (vitamin A) precursors in humans and animals have three isomers (all-trans-RA, 9-cis-RA, and 13-cis-RA), and all-trans-RA and 13-cis-RA are also used in clinical treatment of dermatosis (24) and in cancer prevention and chemotherapy (25). Besides RAs, many endogenous compounds have been reported to be agonists of RARs. Some RA metabolites in humans and animals such as 4-oxo-RA, 4-hydroxy-RA, 18-hydroxy-RA, and 5,6-epoxy-RA can also bind to RARs $(26,27)$. These chemicals could be present in the environment by domestic sewage discharging and medical usage. More recently, a large number of synthetic compounds have also been proven to show RAR agonistic activity in vitro, such as organochlorine pesticides, styrene dimers, monoalkylphenols, and parabens (28-30). To date, few studies have investigated the occurrence 
of potential RAR agonists in aquatic environments $(23,31)$. In a study from Canada, Alsop et al. found that methanol and dichloromethane extracts from three pulp mill effluents were able to displace more than $25 \%$ of the $\left[{ }^{3} \mathrm{H}\right]$ all-trans-RA which bound to RARs from white sucker (Catostomus commersoni) gills (31). Gardiner et al. tested two water samples collected from Minnesota and California ponds and lakes where malformed frogs were frequently discovered, and a high response of RAR $\alpha$ agonistic activity was detected in water samples from both places (23). To the best of our knowledge, however, the causative chemicals have not been identified and no paper has reported the occurrence of RAR agonistic activity in STP effluents and their receiving waters.

In this study, we determined the RAR agonistic activity in seven sewage treatment plants and their receiving rivers in Beijing, China using the RAR $\alpha$ yeast two-hybrid bioassay. Then we identified two causative chemicals applying bioassay-directed HPLC fractionation followed by LC-MS/MS analysis.

\section{Materials and Methods}

Sample Collection. By using flow-proportional samplers, 24-h composite samples of the influents and effluents were collected each day during a one-week period (June 26 to July 2,2006 ) from seven sewage treatment plants (STPs) in Beijing, China. These STPs are all operated with primary and secondary treatment processes without any post disinfection or additional filtration step. All of the plants mainly receive domestic wastewater, and detailed information on the STPs and sampling dates are summarized in Table S1 (Supporting Information). We also collected water samples by single timepoint sampling from the Tonghui River and Qing River (their widths are between 15 and $25 \mathrm{~m}$ ), which receive the effluents from Gaobeidian and Qinghe STP, respectively, in the summer (July 2, 2006) and winter (January 2, 2007). In the Tonghui River, we found two wastewater discharging pipes located at 0.55 and $2.6 \mathrm{~km}$ downstream, which contributed to the water flow in the Tonghui River as well as Gaobeidian STP effluent. Therefore, we set the sampling sites along the Tonghui River at $2 \mathrm{~km}$ upstream, and 0.5, 0.55, 2.55, and 2.6 $\mathrm{km}$ downstream from the discharge point of Gaobeidian STP. The sampling sites for the Qing River were located at 4 and $2 \mathrm{~km}$ upstream, and 2 and $4 \mathrm{~km}$ downstream, of the Qinghe STP. All samples were filtered and extracted within $6 \mathrm{~h}$ after collection. In addition, $300 \mathrm{~mL}$ of human urine was collected from a healthy volunteer, and a $100 \mathrm{~mL}$ fresh swine serum sample was purchased from National Hyclone Bio-Engineering (Lanzhou, China). Additional information about sample collection is provided in the Supporting Information.

Sample Preparation and Solid Phase Extraction (SPE) Fractionation. Water samples were filtered with a $1.2-\mu \mathrm{m}$ pore size Whatman GF/C glass fiber pad (Maidstone, UK). After filtration, the $\mathrm{pH}$ of the samples was adjusted to 3.0 by adding hydrochloric acid. Oasis HLB cartridges $(6 \mathrm{~mL}$, Waters, USA) were conditioned by a sequence of $6 \mathrm{~mL}$ of hexane, 6 $\mathrm{mL}$ of ethyl acetate, $6 \mathrm{~mL}$ of methanol, and $12 \mathrm{~mL}$ of ultrapure water at a flow rate of $5-10 \mathrm{~mL} / \mathrm{min}$. Then $250 \mathrm{~mL}$ of influents, $500 \mathrm{~mL}$ of effluents, and $2 \mathrm{~L}$ of river water were extracted by passing them through $200 \mathrm{mg}, 200 \mathrm{mg}$, and $500 \mathrm{mg}$ cartridges under vacuum at a flow rate of $5-10 \mathrm{~mL} / \mathrm{min}$, respectively. The cartridges were rinsed with $10 \mathrm{~mL}$ of ultrapure water, and then dried under a flow of nitrogen. The dried cartridges were eluted by a sequence of $6 \mathrm{~mL}$ of hexane (F1), $6 \mathrm{~mL}$ of ethyl acetate (F2), and $6 \mathrm{~mL}$ of methanol (F3), respectively. The detailed sample preparation procedure is shown in Figure S1. For the influent and effluent samples, 7-day eluents of each fraction were pooled as composite samples for a complete week. Thus, 1.75 L of influent and 3.5 L of effluent from each STP were finally concentrated to 1.75 and $0.7 \mathrm{~mL}$ for individual fractions, respectively. Mixed eluents were prepared by combining $100 \mu \mathrm{L}$ of each fraction to reach 300 $\mu \mathrm{L}$ in total volume. As for river water, the $2 \mathrm{~L}$ sample was concentrated to $400 \mu \mathrm{L}$ for each fraction, and $100 \mu \mathrm{L}$ of each fraction was combined to get $300 \mu \mathrm{L}$ of mixed eluent. To determine the RAR agonistic activity of STP and river water samples, each fraction $(100 \mu \mathrm{L})$ and the mixed sample (300 $\mu \mathrm{L}$ ) were first concentrated under a gentle stream of nitrogen at room temperature, and then redissolved in $100 \mu \mathrm{L}$ of DMSO. Finally, the concentration factors for the yeast assay of influents, effluents, and river water were 1000, 5000, and 5000, respectively. Experimental blanks were taken by extracting $2 \mathrm{~L}$ of ultrapure water using the same method as described above, and none of them were detected to exhibit RAR agonistic activities. The urine sample was treated using the same procedure as the water samples, and the serum sample was prepared as described in a previous study (32).

Two-Step Reversed-Phase Fractionation Using HPLC and UPLC. For the SPE fraction that showed RAR agonistic activity in the bioassay, a further reversed-phase HPLC fractionation was conducted. Separation was accomplished by a $4.6 \mathrm{~mm} \times 250 \mathrm{~mm}$ symmetry shield RP18 column (Waters, Massachusetts). The column was maintained at room temperature at a flow rate of $1 \mathrm{~mL} / \mathrm{min}$. Solvent A was ultrapure water, and solvent $\mathrm{B}$ was acetonitrile. The gradient was started at $20 \% \mathrm{~B}$, and was held for $3 \mathrm{~min}(0-3 \mathrm{~min})$. Then the gradient was brought to $100 \% \mathrm{~B}$ in $27 \mathrm{~min}(3-30 \mathrm{~min})$, and held for $10 \mathrm{~min}(30-40 \mathrm{~min})$. Finally, the gradient was brought down to $20 \% \mathrm{~B}$ in $0.1 \mathrm{~min}$, and this percentage was kept for $10 \mathrm{~min}(40-50 \mathrm{~min}) \mathrm{until}$ the next injection. The UV detector was set at double wavelengths of 254 and $350 \mathrm{~nm}$. As shown in Figure S1, $1.55 \mathrm{~mL}$ F2 fractions of influents, 0.5 $\mathrm{mL}$ F2 fractions of effluents, and $0.2 \mathrm{~mL}$ F2 fractions of river water samples by SPE from the seven STPs and two rivers were first concentrated under a flow of nitrogen and then fractionated by HPLC. The discrete fractions by HPLC were collected at 2-min intervals. Half of each collection was freezedried for yeast assay, and the other half of each collection was preserved for UPLC/MS/MS analysis. The freeze-dried collections were redissolved in $77.5 \mu \mathrm{L}$ and $50 \mu \mathrm{L}$ DMSO for the influent and effluent, respectively, and therefore the final concentration factors of influent and effluent were 10,000 and 25,000 for the yeast assay. For UPLC-MS/MS analysis, the collections were concentrated under a flow of nitrogen and redissolved in $60 \%$ acetonitrile solution. The final volumes for influents, effluents, and river water were 100 , 100 , and $50 \mu \mathrm{L}$, which made concentration factors of 7750 , 12,500 , and 10,000 for influents, effluents, and river water, respectively. The information of chemicals, UPLC-ESI-MS/ MS condition, and quantitation and quality assurance/quality control (QA/QC) are provided in the Supporting Information.

For the HPLC fraction that showed RAR agonistic activity in the bioassay, ACQUITY ultra-performance liquid chromatography (Waters, Milford, MA) with great improvement of chromatographic resolution was further used for fractionation. Separation was accomplished by a Waters ACQUITY UPLC BEH C18 column $(100 \mathrm{~mm} \times 2.1 \mathrm{~mm}, 1.7 \mu \mathrm{m}$ particle size). The column was maintained at $30{ }^{\circ} \mathrm{C}$ at a flow rate of $0.2 \mathrm{~mL} / \mathrm{min}$. Solvent A was $0.1 \%$ formic acid in ultrapure water, and solvent $B$ was acetonitrile. The isocratic condition with $60 \%$ B was used for chromatographic separation. Fifty $\mu \mathrm{L}$ of the HPLC F15 fraction for influent from Gaobeidian STP, which represents $500 \mathrm{~mL}$ of influent, was fractionated by UPLC (Figure S1). The discrete fractions were collected at 0.5 -min intervals. The collections were first freezedried, and then redissolved in $50 \mu \mathrm{L}$ of DMSO for yeast assay at a concentration factor of 10,000.

Yeast Assay for RAR-mediated Activity. The yeast twohybrid assay described in a previous paper (33) was applied 
to evaluate the RAR-mediated activity of samples, and a detailed description is provided in the Supporting Information.

According to the guide for the derivation and application of relative potency estimates from in vitro bioassay data, multiple-point based estimates would be reasonable to characterize the potency of a variety of samples in in vitro bioassay (34). However, in this study, the responses for most of the STP influent and effluent samples and river water samples were less than $20 \%$ of the maximal response of alltrans-RA in bioassay. Thus, we evaluated the relative potency of samples and calculated the all-trans-RA equivalents (ATRAEQs) based on a single-point estimation using nonlinear regression according to the dose-response curve of all-transRA developed on the same day (34).

\section{Results and Discussion}

RAR $\alpha$ Agonistic Activity in Sewage Treatment Plants. Wastewater samples were extracted and eluted in three fractions, F1, F2 and F3, which represented the nonpolar, medium polar, and polar substances in the samples, and a mixed sample was reconstituted from the three fractions. The RAR $\alpha$ agonistic activity was characterized by comparing the response magnitude caused by samples to the maximum induction by all-trans-RA standard at $100 \mathrm{nmol} / \mathrm{L}$.

Of the three fractions, the F2 fraction exhibited the greatest RAR $\alpha$ agonistic activity in both influents and effluents from all seven STP samples. In the STP influents, the magnitudes of the responses for F2 fractions ranged from $6.1 \%$ (Jiuxianqiao STP) to $21.9 \%$ (Gaobeidian STP) all-trans-RA Max at a concentration factor of 1000 . For the effluent samples, the F2 fractions exhibited magnitudes of responses from $3.6 \%$ (Xiaohongmen STP) to 24\% (Fangzhuang STP) all-trans-RA Max at a concentration factor of 5000. The ATRA-EQ in the $\mathrm{F} 2$ fractions ranged from $6.6 \mathrm{ng} / \mathrm{L}$ (Jiuxianqiao STP) to 13.4 ng/L (Wujiacun STP), and $0.9 \mathrm{ng} / \mathrm{L}$ (Jiuxianqiao STP) to 3.2 ng/L (Fangzhuang STP) for the influent and effluent samples (Table S2), respectively, which indicated that the current treatment processes can effectively remove the RAR $\alpha$ agonists in the F2 fractions of wastewater. Among all the effluents and influents from the seven STPs, only two F1 fractions of influents exhibited weak RAR $\alpha$ agonistic activity (Figure 1). The F1 fraction mainly contained nonpolar compounds. As for the F3 fractions, no significant RAR $\alpha$ agonistic activities were observed in any of the samples.

For the mixed samples of three fractions, only one of the seven STP influents showed weak RAR $\alpha$ agonistic activity, while three of the seven STP effluents exhibited relatively strong RAR $\alpha$ agonistic activities (Figure 1). Since all F2 fractions were observed to exhibit RAR $\alpha$ agonistic activities, this phenomenon would be explained by the presence of the matrix. Thus, the mixed samples of three fractions were spiked by $50 \mu \mathrm{g} / \mathrm{L}$ all-trans-RA, and the inhibition was estimated (Supporting Information) to be up to $86-103 \%$ in the influents of Fangzhuang, Beixiaohe, Jiuxianqiao, and Qinghe STPs and about $67 \%$ in the effluents except for Fangzhuang STP $(97 \%)$.

RAR $\alpha$ Agonistic Activity in Receiving River Waters. To investigate the occurrence of RAR agonists in river water due to the discharge of STP effluents, we collected water samples from the Tonghui River and Qing River, which received the effluents from Gaobeidian STP and Qinghe STP, respectively. The water samples were taken in the summer (July 2006) and winter (January 2007) from upstream and downstream of the STP discharging sites.

Similar to the results for the samples from the STPs, significant RAR $\alpha$ agonistic activities in river water samples were observed in the F2 fractions from both the Tonghui River and Qing River (Figure 2), and their corresponding ATRA-EQ values are listed in Tables S3 and S4. It should be

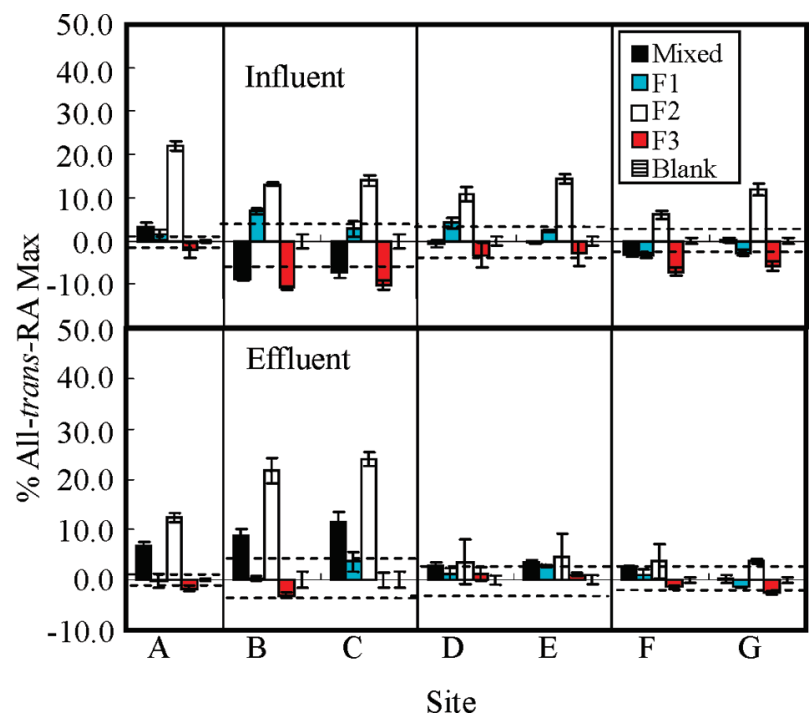

FIGURE 1. RAR $\alpha$ agonistic activity of the influents (upper panels) and effluents (lower panels) in the seven Beijing sewage treatment plants during summer 2006. The concentration factors for influent and effluent are 1000 and 5000, respectively. Response magnitude stands for the percentage of the average maximum response observed for a $100 \mathrm{nmol} / \mathrm{L}$ all-trans-RA standard (\% All-trans-RA Max). Dashed lines represent \pm 3 standard derivation (SD) from the mean solvent control response (set to $0 \%$ All-trans-RA Max): A Gaobeidian; B Beixiaohe; C Fangzhuang; D Xiaohongmen; E Wujiacun; F Jiuxianqiao; G Oinghe.

noted that two samples taken from downstream Tonghui River ( 0.55 and $2.6 \mathrm{~km}$ downstream) in both the summer and winter exhibited unexpectedly high responses of RAR $\alpha$ agonistic activities, even higher than the activities in the corresponding STP effluents, indicating that there were other input sources in both rivers. In a previous paper reporting on the occurrence of natural and synthetic glucocorticoids at the same sites in the Tonghui River, it was also found that the concentrations of glucocorticoids were unexpectedly higher than those in the corresponding STP effluent samples (35). These elevated concentrations are most likely caused by a wastewater discharging pipe at the $0.55 \mathrm{~km}$ site (Pipe 1) which contributed greatly to the total load of glucocorticoids in downstream river. Thus, we collected the wastewater (in January 2007) from Pipe 1 ( $0.55 \mathrm{~km}$ downstream) and Pipe 2 (2.6 km downstream), and found that the F2 fractions of the samples from Pipes 1 and 2 exhibited much higher RAR $\alpha$ agonistic activities than the river water at 0.55 and $2.6 \mathrm{~km}$ downstream, respectively. The ATRA-EQ in the two samples from Pipes 1 and 2 were calculated to be 67 and $94 \mathrm{ng} / \mathrm{L}$, which were 9.4 and 11.3 times those of samples taken from the corresponding river sites, 7.1 and $8.3 \mathrm{ng} / \mathrm{L}$, respectively (Table S3). As for the sample taken from upstream Tonghui River ( $2 \mathrm{~km}$ upstream), the RAR $\alpha$ agonistic activities in F2 fractions were slightly higher than those from Gaobeidian STP effluents in both the summer and winter, which might be due to the undiscovered discharging sources along the upstream Tonghui River.

On the other hand, two samples from upstream (4 and $2 \mathrm{~km}$ upstream) of the Qing River in both summer and winter exhibited unexpectedly high responses of RAR $\alpha$ agonistic activities. Such distribution along the Qing River is different from that of natural and synthetic glucocorticoids at the same sites in the Qing River (35). Considering that the glucocorticoids are originally from the discharge of humans and animals, the unexpectedly high $\operatorname{RAR} \alpha$ agonistic activities might be due to the discharge of other unknown sources, which needs further investigation. It is interesting that the 


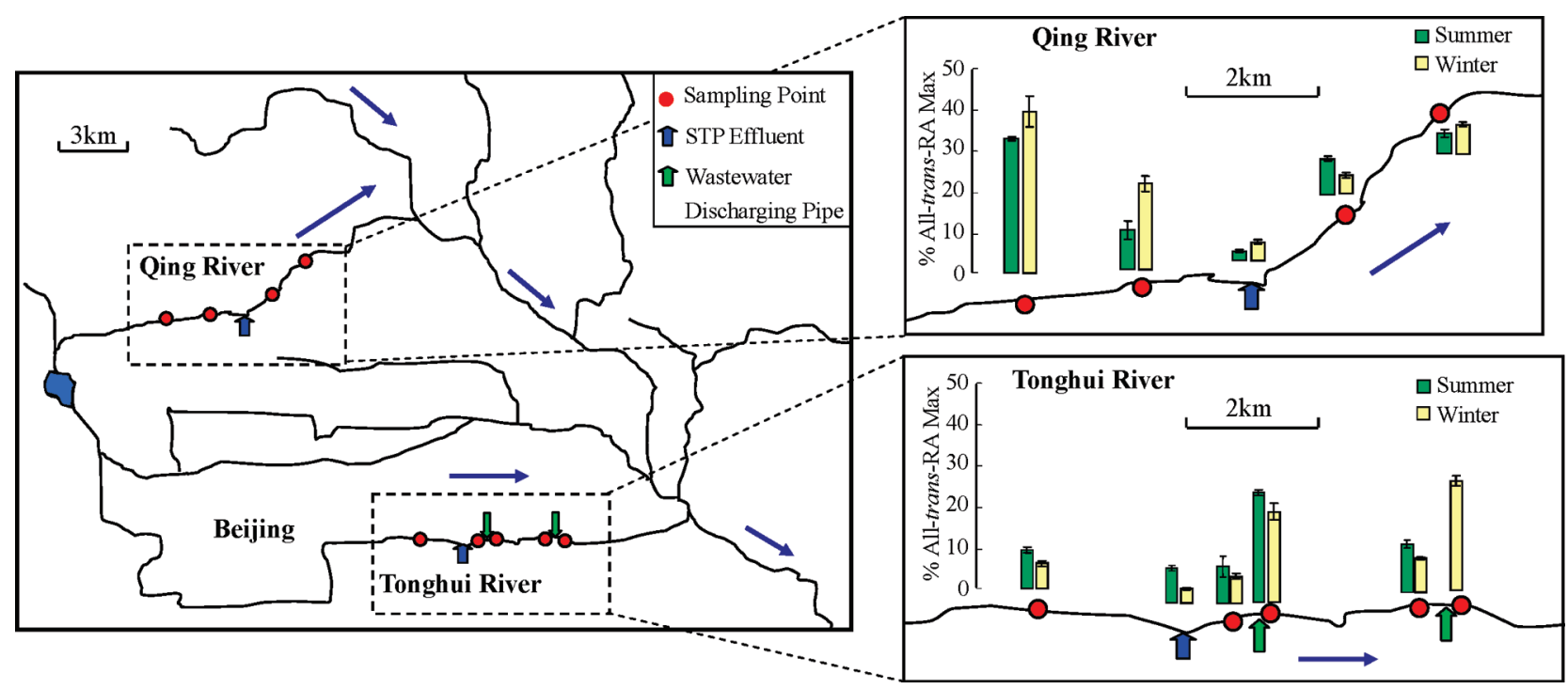

FIGURE 2. RAR $\alpha$ agonistic activity of water samples (F2 fractions) extracted from the Tonghui River and Qing River at different distances from the corresponding STPs. The concentration factor for river water is 5000 . Response magnitude stands for the percentage of the average maximum response observed for a $100 \mathrm{nmol} / \mathrm{L}$ all-trans-RA standard (\% All-trans-RA Max).

two F3 samples taken from upstream sites (4 and $2 \mathrm{~km}$ upstream) of the Qing River in the summer caused significant responses in RAR $\alpha$ agonistic activity tests, and this activity was comparable to that of the F2 fraction, while no detection was found in the sample taken in the winter, showing an obvious seasonal variation. However, no activity was detected in the F3 fractions of STP samples which were also taken in the summer. The reason for this difference of F3 fractions between STP and river samples is not clear, and needs to be investigated further.

Identification of RAR Agonists in Sewage Treatment Plants. As noted above, the major RAR $\alpha$ agonists in both STP waters and river waters were present in the F2 fraction,

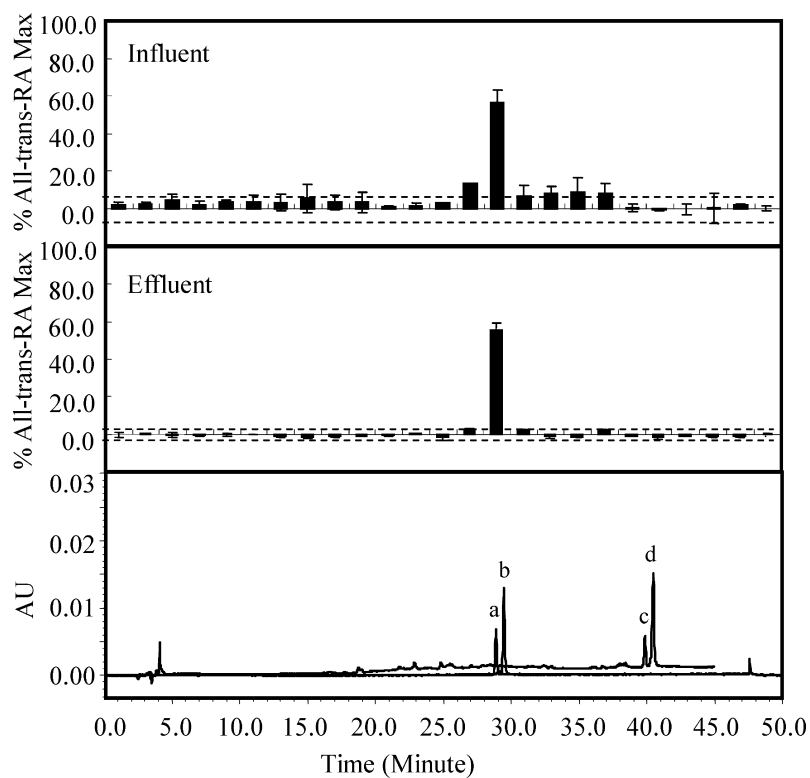

FIGURE 3. RAR $\alpha$ agonistic activity profiles produced from F2 fractions of Gaobeidian STP influent (upper panel) and effluent (middle panel) using a bioassay-directed HPLC fractionation method. The concentration factors for influent and effluent are 10,000 and 25,000 , respectively. The lower panel presents the chromatograph of several RAR agonists in HPLC with UV

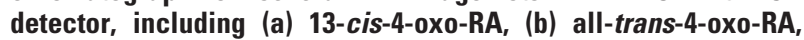
(c) 13-cis-RA, and (d) all-trans-RA and 9-cis-RA. The detection wavelength is $350 \mathrm{~nm}$ for endogenous RAs.

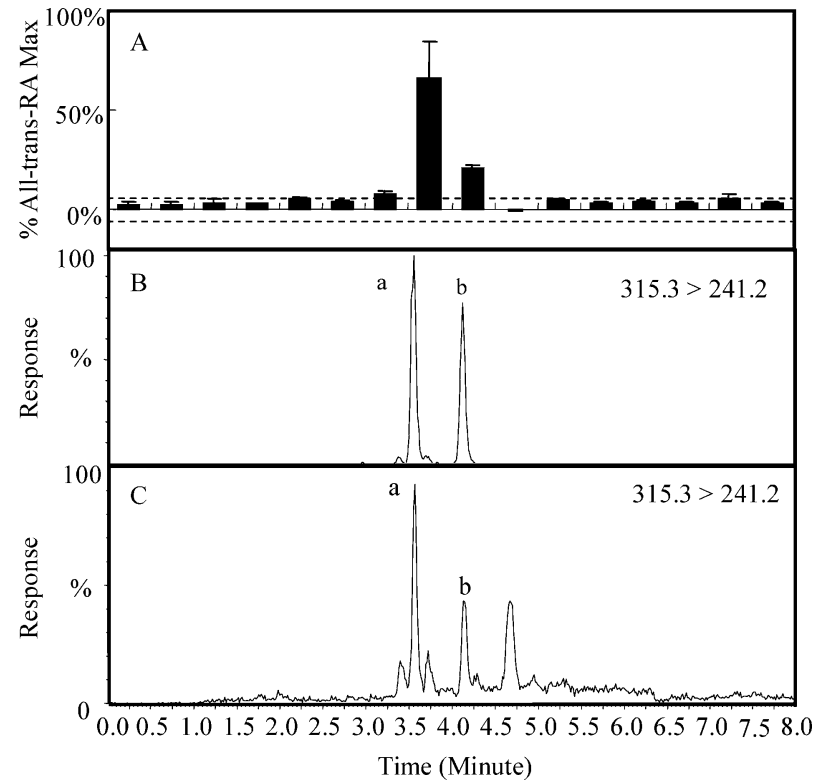

FIGURE 4. (A) RAR $\alpha$ agonistic activity profiles of HPLC F15 fraction from Gaobeidian STP influent using bioassay-directed UPLC fractionation methods; (B) UPLC/MS/MS chromatograms of (a) all-trans-4-0xo-RA and (b) 13-cis-4-0xo-RA in mixed standards; and (C) UPLC/MS/MS chromatograms of (a) all-trans-4-0xo-RA and (b) 13-cis-4-oxo-RA in an influent sample of Gaobeidian STP.

a midpolar fraction. Thus, we further investigated the specific RAR agonists in aquatic environments using a bioassaydirected HPLC fractionation method. We fractionated F2 fractions of SPE samples from the effluents of all seven STPs and one influent, and found that the major RAR $\alpha$ agonistic activities in all the samples occurred at the 15th fraction (HPLC F15) corresponding with a retention time between 28 and $30 \mathrm{~min}$ (Figure 3), indicating that this fraction is responsible for the main RAR $\alpha$ agonistic activities in the STP samples.

To characterize the chemicals causing the response in the bioassay, we tested the RAR $\alpha, \beta$, and $\gamma$ agonistic activities of the HPLC F15 to get the phenotype of this fraction, and tried to compare the phenotype with those of already-known RAR agonists. As shown in Figure S4, both the RAR agonistic 
TABLE 1. Concentrations (ng/L) of all-trans-4-oxo-RA, 13-cis-4-0xo-RA $(n=3)$, and the Chemical-Derived all-trans-RA Equivalents $\left(A T R A-E_{\text {cal }}\right)$ in the Seven STP Influents and Effluents

\begin{tabular}{|c|c|c|c|c|c|c|}
\hline & \multicolumn{2}{|c|}{ all-trans-4-0x0-RA } & \multicolumn{2}{|c|}{ 13-cis-4-0xo-RA } & \multicolumn{2}{|c|}{ ATRA-EO cal } \\
\hline & influent & effluent & influent & effluent & influent & effluent \\
\hline Gaobeidian & $5.9 \pm 0.2$ & $0.5 \pm 0.1$ & $2.7 \pm 0.1$ & $0.4 \pm 0.1$ & 23 & 2.0 \\
\hline Beixiaohe & $4.7 \pm 1.1$ & $0.5 \pm 0.0$ & $2.5 \pm 0.6$ & $1.1 \pm 0.4$ & 18 & 2.3 \\
\hline Fangzhuang & $10.4 \pm 1.1$ & $0.9 \pm 0.1$ & $7.1 \pm 1.8$ & $0.8 \pm 0.2$ & 41 & 3.7 \\
\hline Xiaohongmen & $5.3 \pm 0.2$ & $\mathrm{nd}^{a}$ & $3.1 \pm 0.4$ & $1.0 \pm 0.4$ & 21 & 0.8 \\
\hline Wujiacun & $4.8 \pm 0.6$ & nd & $2.3 \pm 0.1$ & nd & 19 & 0.5 \\
\hline Jiuxianqiao & $4.8 \pm 0.7$ & nd & $2.6 \pm 0.1$ & $0.7 \pm 0.1$ & 19 & 0.7 \\
\hline Qinghe & $4.9 \pm 0.7$ & nd & $2.7 \pm 0.0$ & nd & 19 & 0.5 \\
\hline
\end{tabular}

activity profile of HPLC F15 in three subtypes (sensitivity decreased in the order of $\alpha>\gamma>\beta$ ) and its maximal activities are highly similar to those of all-trans-RA, suggesting that the RAR agonists in HPLC F15 might have a chemical structure similar to all-trans-RA. Therefore, the swine serum and human urine samples were also fractionated by HPLC, and significant RAR $\alpha$ agonistic activities were also detected in the HPLC F15 of both samples. These results indicated that the RAR agonists in wastewater are endogenous RAs. To identify the potential chemical, three isomers of RA including all-trans-RA, 13-cis-RA, and 9-cis-RA were injected into the HPLC system. However, the peaks of the three isomers of RA did not overlap with HPLC F15 (Figure 3), indicating that these RAs were not the causative chemicals for the RAR agonistic activity in wastewater.

Thus, we tested two commercially obtainable metabolites of RAs, all-trans-4-oxo-RA and 13-cis-4-oxo-RA, which were reported to exhibit relatively high RAR-ligand affinity $(26,27)$. In our yeast assay for RAR $\alpha$-mediated activity, the $\mathrm{EC}_{50}$ for all-trans-4-oxo-RA was determined to be $0.32 \mathrm{nmol} / \mathrm{L}$, much lower than all-trans-RA $(1.35 \mathrm{nmol} / \mathrm{L})$, while the $\mathrm{EC}_{50}$ for 13-cis-4-oxo-RA (3.2 nmol/L) was higher than that of alltrans-RA, as shown in Figure S5. The $\mathrm{EC}_{50}$ for all-trans-4oxo-RA or 13-cis-4-oxo-RA relative to that of all-trans-RA was defined as its all-trans-RA equivalency factor (RAEF), which was calculated to be 3.87 and 0.46 , respectively. As shown in Figure 3, the peaks of two isomers of 4-oxo-RA were observed at the retention times of $28.9 \mathrm{~min}$ (13-cis-4oxo-RA) and $29.5 \mathrm{~min}$ (all-trans-4-oxo-RA), which overlapped with HPLC F15, suggesting that the 4-oxo-RAs might be the agonists of RAR in the samples. To further identify the causal chemicals inducing the RAR $\alpha$ agonistic activity, UPLC fractionation for HPLC F15 from Gaobeidian STP influent was carried out, and the RAR $\alpha$ activities of the fractions were also determined. As shown in Figure 4, the two bioactive fractions were found at the retention times of 3.5-4.0 min and 4.0-4.5 $\mathrm{min}$ (Figure 4A), overlapping with all-trans-4oxo-RA and 13-cis-4-oxo-RA standards at 3.55 and $4.13 \mathrm{~min}$, respectively (Figure 4B). In the influent sample (Figure $4 \mathrm{C}$ ), two peaks were also found at 3.55 and 4.13 min by detecting a $315 \mathrm{~m} / z$ to $241 \mathrm{~m} / z$ MRM transition, which were highly suspected to be all-trans-4-oxo-RA and 13-cis-4-oxo-RA. Figure S6 shows the MS/MS spectra of the base peak ion of $m / z 315$ (ESI positive ion mode) in two bioactive fractions, and we found that the mass spectra at 3.55 and $4.13 \mathrm{~min}$ are highly similar to those of all-trans-4-oxo-RA and 13-cis-4oxo-RA standards (Figure S2), suggesting that all-trans-4oxo-RA and 13-cis-4-oxo-RA contributed to the RAR agonistic activity in the STP.

The HPLC F15 samples in the seven STPs, of which the RAR $\alpha$ agonistic activities were reported above, were also analyzed by UPLC-ESI-MS/MS, and the concentrations in the influent and effluent samples without recovery correction are listed in Table 1. The concentrations of all-trans-4-oxoRA were in the range of 4.7 to $10.4 \mathrm{ng} / \mathrm{L}$ in influents and below detection limit $(<0.2 \mathrm{ng} / \mathrm{L})$ to $0.9 \mathrm{ng} / \mathrm{L}$ in effluents, while the concentrations of 13-cis-4-oxo-RA were in the range of 2.3 to $7.1 \mathrm{ng} / \mathrm{L}$ in influents and below detection limit $(<0.4$ $\mathrm{ng} / \mathrm{L}$ ) to $1.1 \mathrm{ng} / \mathrm{L}$ in effluents. Based on the concentrations of all-trans-4-oxo-RA and 13-cis-4-oxo-RA and their RAEF values, the chemical-derived all-trans-RA equivalents (ATRA$\mathrm{EQ}_{\mathrm{cal}}$ ) were calculated to be in the ranges of $18 \mathrm{ng} / \mathrm{L}$ (Beixiaohe STP) to $41 \mathrm{ng} / \mathrm{L}$ (Fangzhuang STP) and $0.5 \mathrm{ng} / \mathrm{L}$ (Wujiacun STP) to $3.7 \mathrm{ng} / \mathrm{L}$ (Fangzhuang STP) in influent and effluent, respectively.

For the river water samples, the concentrations of alltrans-4-oxo-RA were in the range of below detection limit $(<0.2 \mathrm{ng} / \mathrm{L})$ to $1.0 \mathrm{ng} / \mathrm{L}$ in summer and $<0.2$ to $1.8 \mathrm{ng} / \mathrm{L}$ in winter, while the concentrations of 13-cis-4-oxo-RA were in the ranges of below detection limit $(<0.4 \mathrm{ng} / \mathrm{L})$ to $1.6 \mathrm{ng} / \mathrm{L}$ in summer and $<0.4$ to $1.5 \mathrm{ng} / \mathrm{L}$ in winter (Tables S5 and S6). It should be noted that the ATRA-EQ cal $_{\text {of }}$ samples taken at 4 and $2 \mathrm{~km}$ upstream Qing River in summer were much lower than the corresponding ATRA-EQ values derived from bioassay (Table S4), suggesting that there would be other unidentified RAR agonists in the river water and need to be studied further.

Previous studies have reported that all-trans-4-oxo-RA and 13-cis-4-oxo-RA widely exist in human and animal serum $(36,37)$ and can be eliminated from the body through urinary excretion (38). In another study, Li et al. also detected the glucuronide conjugate of all-trans-4-oxo-RA and 13-cis-4oxo-RA in urine of rats that had been fed with all-trans-RA, 9-cis-RA, and 13-cis-RA previously (39). Thus, it is possible that all-trans-4-oxo-RA and 13-cis-4-oxo-RA can be produced through deconjugation of their glucuronides in wastewater treatment plants or rivers. In this study, however, we did not aim at the fates of all-trans-4-oxo-RA and 13-cis-4-oxo-RA in STP and their receiving river waters, and there is a need for further study.

All-trans-4-oxo-RA has been found to be much more active than all-trans-RA in causing microcephaly in Xenopus laevis embryos (27). In this study, the causal chemicals inducing RAR activity in the environment were identified for the first time, and there is a need to further investigate their occurrence, fates, and ecotoxicity to assess their ecological risk.

\section{Acknowledgments}

Financial support from the National Natural Science Foundation of China [20777002, 40632009], National Basic Research Program of China [2007CB407304], and Japan New Energy and Industrial Technology Development Organization is gratefully acknowledged.

\section{Supporting Information Available}

Additional tables and figures. This material is available free of charge via the Internet at http://pubs.acs.org. 


\section{Literature Cited}

(1) Purdom, C. E.; Hardiman, P. A.; Bye, V. J.; Eno, N. C.; Tyler, C. R.; Sumpter, J. P. Estrogenic effects of effluents from sewage treatment works. Chem. Ecol. 1994, 8, 275-285.

(2) Jobling, S.; Nolan, M.; Tyler, C. R.; Brighty, G.; Sumpter, J. P. Widespread sexual disruption in wild fish. Environ. Sci. Technol. 1998, 32, 2498-2506.

(3) Bell, B.; Spotila, J. R.; Congdon, J. High incidence of deformity in aquatic turtles in the John Heinz National Wildlife refuge. Environ. Pollut. 2006, 142, 457-465.

(4) Kingsford, M. J.; Suthers, I. M.; Gray, C. A. Exposure to sewage plumes and the incidence of deformities in larval fishes. Mar. Pollut. Bull. 1996, 33, 201-212.

(5) Desbrow, C.; Routledge, E. J.; Brighty, G. C.; Sumpter, J. P.; Waldock, M. Identification of estrogenic chemicals in STW effluent. 1. Chemical fractionation and in vitro biological screening. Environ. Sci. Technol. 1998, 32, 1549-1558.

(6) Snyder, S. A.; Villeneuve, D. L.; Snyder, E. M.; Giesy, J. P. Identification and quantification of estrogen receptor agonists in wastewater effluents. Environ. Sci. Technol. 2001, 35, 36203625.

(7) Rudel, R. A.; Melly, S. J.; Geno, P. W.; Sun, G.; Brody, J. G. Identification of alkylphenols and other estrogenic phenolic compounds in wastewater, septage, and groundwater on Cape Cod, Massachusetts. Environ. Sci. Technol. 1998, 32, 861-869.

(8) Chawla, A.; Repa, J. J.; Evans, R. M.; Mangelsdorf, D. J. Nuclear Receptors and Lipid Physiology: Opening the X-Files. Science 2001, 294, 1866.

(9) Vos, J. G.; Dybing, E.; Greim, H. A.; Ladefoged, O.; Lambré, C.; Tarazona, J. V.; Brandt, I.; Vethaak, A. D. Health effects of endocrine-disrupting chemicals on wildlife, with special reference to the European situation. Crit. Rev. Toxicol. 2000, 30, 71-133.

(10) Nishikawa, J.; Mamiya, S.; Kanayama, T.; Nishikawa, T.; Shiraishi, F.; Horiguchi, T. Involvement of the retinoid X receptor in the development of imposex caused by organotins in gastropods. Environ. Sci. Technol. 2004, 38, 6271-6276.

(11) Gudas, L. J.; Sporn, M. B.; Roberts, A. B. In The Retinoids: Biology, Chemistry, and Medicine; Sporn, M. B., Roberts, A. B., Goodman, D. S., Eds.; Raven Press: New York, 1994; pp 443-520.

(12) Collins, M. D.; Mao, G. E. Teratology of retinoids. Annu. Rev. Pharmacol. Toxicol. 1999, 39, 399-430.

(13) Chambon, P. A decade of molecular biology of retinoic acid receptors. FASEB J. 1996, 10, 940-954.

(14) Haga, Y.; Suzuki, T.; Takeuchi, T. Retinoic Acid isomers produce malformations in postembryonic development of the Japanese flounder Paralichthys olivaceus. Zool. Sci. 2002, 19, 1105-1112.

(15) Scadding, S. R.; Maden, M. Comparison of the effects of vitamin A on limb development and regeneration in Xenopus laevis tadpoles. J. Embryol. Exp. Morphol. 1986, 91, 35-53.

(16) Scadding, S. R.; Maden, M. The effects of local application of retinoic acid on limb development and regeneration in tadpoles of Xenopus laevis. J. Embryol. Exp. Morphol. 1986, 91, 55-63.

(17) Degitz, S. J.; Kosian, P. A.; Makynen, E. A.; Jensen, K. M.; Ankley, G. T. Stage- and Species-Specific Developmental Toxicity of All-Trans Retinoic Acid in Four Native North American Ranids and Xenopus laevis. Toxicol. Sci. 2000, 57, 264-74.

(18) Alsop, D. H.; Brown, S. B.; van der Kraak, G. J. Dietary retinoic acid induces hindlimb and eye deformities in Xenopus laevis. Environ. Sci. Technol. 2004, 38, 6290-6299.

(19) Gardiner, D. M.; Hoppe, D. M. Environmentally induced limb malformation in mink frogs (Rana septentrionalis). J. Exp. Zool. 1999, 284, 207-216.

(20) Meteyer, C. U.; Loeffler, I. K.; Fallon, J. F.; Converse, K. A. Hind limb malformations in free-living northern leopard frogs (Rana pipiens) from Maine, Minnesota, and Vermont suggest multiple etiologies. Teratology 2000, 62, 151-171.

(21) Ouellet, M.; Bonin, J.; Rodrigue, J.; DesGranges, J. L.; Lair, S. Hindlimb deformities (ectromelia, ectrodactyly) in free-living anurans from agricultural habitats. J. Wildlife Dis. 1997, 33, 95-104.
(22) Taylor, B.; Skelly, D.; Demarchis, L. K.; Slade, M. D.; Galusha, D.; Rabinowitz, P. M. Proximity to pollution sources and risk of amphibian limb malformation. Environ. Health Perspect. 2005, 113, 1497-1501.

(23) Gardiner, D.; Ndayibagira, A.; Grun, F.; Blumberg, B. Deformed frogs and environmental retinoids. Pure Appl. Chem. 2003, 75, 2263-2273.

(24) Peck, G. L.; DiGiovanna, J. J. In The Retinoids: Biology, Chemistry, and Medicine; Sporn, M. B.; Roberts, A. B., Goodman, D. S., Eds.; Raven Press: New York, 1994; pp 631-658.

(25) Hong, W. K.; Itri, L. M. In The Retinoids: Biology, Chemistry, and Medicine; Sporn, M. B., Roberts, A. B., Goodman, D. S., Eds.; Raven Press: New York, 1994; pp 597-630.

(26) Idres, N.; Marill, J.; Flexor, M. A.; Chabot, G. G. Activation of retinoic acid receptor-dependent transcription by all-transretinoic acid metabolites and isomers. J. Biol. Chem. 2002, 277, 31491-31498.

(27) Pijnappel, W. W. M.; Hendriks, H. F. J.; Folkers, G. E.; van den Brink, C. E.; Dekker, E. J.; Edelenbosch, C.; van der Saag, P. T.; Durston, A. J. The retinoid ligand 4-oxo-retinoic acid is a highly active modulator of positional specification. Nature 1993, 366, 340-344.

(28) Lemaire, G.; Balaguer, P.; Michel, S.; Rahmani, R. Activation of retinoic acid receptor-dependent transcription by organochlorine pesticides. Toxicol. Appl. Pharmacol. 2005, 202, 38-49.

(29) Kanayama, T.; Kobayashi, N.; Mamiya, S.; Nakanishi, T.; Nishikawa, J. Organotin compounds promote adipocyte differentiation as agonists of the Peroxisome Proliferator-Activated Receptor $\gamma /$ Retinoid X Receptor Pathway. Mol. Pharmacol. 2005, 67, 766-774.

(30) Kamata, R.; Shiraishi, F.; Nishikawa, J.; Yonemoto, J.; Shiraishi, H. Screening and detection of the in vitro agonistic activity of xenobiotics on the retinoic acid receptor. Toxicol. Vitro 2008, 22, 1050-61.

(31) Alsop, D.; Hewitt, M.; Kohli, M.; Brown, S.; van der Kraak, G. Constituents within pulp mill effluent deplete retinoid stores in white sucker and bind to rainbow trout retinoic acid receptors and retinoid X receptors. Environ. Toxicol. Chem./SETAC 2003, 22, 2969-2976.

(32) Schmidt, C. K.; Volland, J.; Hamscher, G.; Nau, H. Characterization of a new endogenous vitamin A metabolite. Biochim. Biophys. Acta Mol. Cell Biol. Lipids 2002, 1583, 237-251.

(33) Nishikawa, J.; Saito, K.; Goto, J.; Dakeyama, F.; Matsuo, M.; Nishihara, T. New screening methods for chemicals with hormonal activities using interaction of nuclear hormone receptor with coactivator. Toxicol. Appl. Pharmacol. 1999, 154, 76-83.

(34) Villeneuve, D. L.; Blankenship, A. L.; Giesy, J. P. Derivation and application of relative potency estimates based on in vitro bioassay results. Environ. Toxicol. Chem./SETAC 2000, 19, 28352843.

(35) Chang, H.; Hu, J. Y.; Shao, B. Occurrence of natural and synthetic glucocorticoids in sewage treatment plants and receiving river waters. Environ. Sci. Technol. 2007, 41, 3462-3468.

(36) Gundersen, T.E.; Blomhoff, R. Qualitative and quantitative liquid chromatographic determination of natural retinoids in biological samples. J. Chromatogr. A 2001, 935, 13-43.

(37) Wyss, R.; Bucheli, F. Determination of endogenous levels of 13-cis-retinoic acid (isotretinoin), all-trans-retinoic acid (tretinoin) and their 4-oxo metabolites in human and animal plasma by high-performance liquid chromatography with automated column switching and ultraviolet detection. J. Chromatogr. B 1997, 700, 31-47.

(38) Marill, J.; Idres, N.; Capron, C. C.; Nguyen, E.; Chabot, G. G. Retinoic acid metabolism and mechanism of action: a review. Curr. Drug Metab. 2003, 4, 1-10.

(39) Li, S.; Barua, A. B.; Huselton, C. A. Quantification of retinoyl$\beta$-glucuronides in rat urine by reversed phase high-performance liquid chromatography with ultraviolet detection. J. Chromatogr. B 1996, 683, 155-162.

ES9000328 